\title{
A Comparison of the Effects of Organizational Environment and Individual Factors on Male and Female Faculty Teaching Efficacy in Vietnam
}

\author{
Minh-Quang Duong \\ University of Social Sciences and Humanities, \\ Vietnam National University of Ho Chi Minh City \\ 10-12 Dinh Tien Hoang Street, District 1, Ho Chi Minh City, Vietnam \\ E-mail: duongminhquang@hcmussh.edu.vn
}

Received: September 17, 2017 Accepted: October 14, 2017 Published: October 17, 2017

doi:10.5296/elr.v3i2.11875

URL: http://doi.org/10.5296/elr.v3i2.11875

\begin{abstract}
The purpose of this study examined the correlation between factors of teaching efficacy and their relation to faculty members' backgrounds, and how organizational environment factors affect faculty teaching efficacy in male versus female populations. A questionnaire measuring six factors of teaching efficacy was distributed to 124 university faculty members in Vietnam. The finding of this study indicated that it was relatively high positive correlation between factors of teaching efficacy. Comparative results of male and female faculty members in various contexts detected using a statistical method and criteria demonstrated that almost individual factors including marital status, age groups, and academic rank were not significant in the male and female faculty teaching efficacy, except educational attainment factor. In addition, both genders were similarly affected by their organizational environment as far as teaching efficacy is concerned. The study's implications for university management were also discussed.
\end{abstract}

Keywords: Teaching efficacy, Organizational environment, Individual factor, Gender, Faculty member

\section{Introduction}

Responding to the major change of nation development, Vietnamese universities underwent various reforms with a core task to cultivate high-quality human resources, predominantly economic professionals and leaders, to facilitate the industrialization and modernization of Vietnam (Hayden \& Lam, 2007; Ngo, Lingard, \& Mitchell, 2006). However, Vietnamese 
higher education continues to face challenges. The centralized system of control and governance did not promote the improvement of training quality of the whole system, and does not encourage the creativity of instructors, education administrators and students (Hayden \& Lam, 2007). The major responsibilities of faculty in the university are essentially three including teaching, research, and service (Marsh \& Hattie, 2003; Shen, 1997). Especially, teaching is viewed as the primary function of university faculty in Vietnam (The National Assembly, 2012). The teaching effectiveness of faculty members in the Vietnamese universities play a very important role in enhances the education quality.

Teaching efficacy is "a judgment about capabilities to influence student engagement and learning, even among those students who may be difficult or unmotivated (Woolfolk Hoy, 2004, p. 1). According to Tschannen-Moran, Woolfolk Hoy and Hoy (1998, p. 232), teaching efficacy is considered as "teacher's belief in his or her capability to organize and execute courses of action required to successfully accomplish a specific teaching task in a particular context".

Teaching efficacy was developed in Bandura's (1997) social cognitive and self-efficacy theories. Bandura (1986, p. 31) defined self-efficacy as "people's judgment of their capabilities to organize and execute courses of action required to attain designated types of performances". The research of Bandura showed that self-efficacy is a key concept of social cognitive theory which was that behavior is best understood in terms of a triadic reciprocal system. Cook (1998, p. 14) identified that "teaching efficacy is not only an observable behavior, but also rather an individual belief".

The selection of positive teaching behaviors, efficacious teachers tend to have high student achievement. Ross (1994) suggested teachers with high sense of efficacy tend to be more use: 1) new approaches, 2) management techniques, 3) help students who had low academic achievement, 4) develop students' academic skills, 5) set attainable goals, and 6) persist in the face of student failure. Similarly, Woolfolk Hoy (2004) showed that teachers with a strong sense of efficacy spend more time teaching in areas, and are more open to new ideas, more willing to experiment with new methods, more committed to teaching, and tend to exhibit greater levels of planning, organization, and enthusiasm (Allinder, 1994). Overall, teacher efficacy tends to engage in more productive, quality teacher behaviors (Ashton \& Webb, 1986; Gibson \& Dembo, 1984).

Almost studies have focused on the teachers' teaching efficacy in the elementary and secondary schools (Lin \& Gorrell, 2001; Tschannen-Moran \& Woolfolk Hoy, 2002) and little is known about the faculty teaching efficacy in higher education (Cook, 1998). However, there are some studies on effective teaching in higher education to focus on teaching conceptions. The research of Brown (1993) measured faculty teaching efficacy in five factors, including course design, use of media, class management, teacher-student interaction, assessment and feedback to students. Gow and Kember (1993) found nine subscales of teaching conceptions, such as: training for specific jobs, imparting information, knowledge of subjects, problem solving, motivator of students, use of media, facilitative teaching, pastoral interest, and interactive teaching. According to Mehdinezhad (2012), faculty members' self-ratings of their teaching efficacy clustered around six teaching self-efficacy factors: subject matters or content knowledge, curriculum and instruction knowledge, interaction or 


\section{MInstitute Macrothink $_{\text {Int }}$}

communication competencies, evaluation of learning or assessment, knowledge of the learning environment and implementing technology in the curriculum. In this study, we used 27 items of six factors of teaching efficacy by research of Chang, McKeachie, and Lin (2010). They included course design, instructional strategy, technology usage, class management, interpersonal interaction, and learning assessment. The faculty teaching efficacy in this study is defined by Chang et al. (2010), Tschannen-Moran and Woolfolk Hoy (2001) as the faculty members' judgment of their capabilities in course design, instructional strategy, technology usage, classroom management, interpersonal relation, and learning assessment.

Several studies showed that there were related factors influencing faculty teaching efficacy. Studies have shown that teaching efficacy affected student achievement (Esterly, 2003; Henson, 2001), student success (Tournaki \& Podell, 2005; Woolfolk-Hoy \& Davis, 2006), student learning motivation (Nolen, Ward, Horn, Campbell, Mahna, \& Childers, 2007), and student effectiveness (Tschannen-Moran \& Woolfok-Hoy, 2001; Usher \& Pajares, 2006). Research of Goddard, Hoy and Woolfolk Hoy (2000) demonstrated that faculty teaching efficacy is related to students' academic achievement, intrinsic motivation, and learning efficacy. Tschannen-Moran, Woolfolk Hoy and Hoy (1998) identified that teacher efficacy has been connected with student attitudes, teachers' classroom behaviors, teachers' attitudes, teacher stress and burnout, and teachers' willingness to implement innovation. Furthermore, Research shows that teaching efficacy related to different psychological factors of the instructor, such as willingness to accept new ideas (Brouwers \& Tomic, 2003; Henson, 2001, Ross \& Bruce, 2007), persistence for student dissatisfaction (Gibson \& Dembo, 1984), spend time for teaching per semester (Kim, 2009), and teacher assessment (Gkolia \& Belias, \& Koustelios, 2014; Carara, Barbaranelli, Steca, \& Malone, 2006), classroom management behavior (Giallo \& Little, 2003; Henson, 2001), responsibility for student learning (Darling-Hammond, Chung, \& Frelow, 2002), trust and openness (Goddard, Hoy, \& Woolfolk-Hoy, 2004), and happiness of teacher (Mehdinezhad, 2012). However, there is as yet no empirical research on the effects between faculty teaching efficacy and organizational environment factors (e.g, teaching resources, organizational culture, remuneration policy, and administrative support) or comparison among male and female faculty teaching efficacy with different individual factors.

It is clear that very few studies have been conducted in the area of teaching efficacy in Vietnamese higher education sector. The findings of this study, therefore, contribute to fill in the literature gap of faculty teaching efficacy in higher education. It identifies and discusses factors in Vietnamese university faculty's teaching efficacy which contribute most to their teaching performance and students' learning achievement. The purpose of this study examined the correlation between factors of teaching efficacy and their relation to faculty members' backgrounds, and how organizational environment factors affect faculty teaching efficacy in male versus female populations. The present study focuses on the following three research questions: 1) How is the correlation between factors of faculty teaching efficacy in Vietnam? 2) Do any significant differences exist in the level of male and female faculty teaching efficacy regarding individual factors? and 3) How are male and female faculty teaching efficacy affected by organizational environment factors? 


\section{Research Method}

\subsection{Sample}

The authors designed and implemented a survey and distributed to 124 faculty members who were drawn from faculty members to working full-time in the University of Social Sciences and Humanities (USSH) - one of six member universities of Vietnam National University of Ho Chi Minh City (VNU - HCM). All data of respondents were self-reported information which was prevalently used in higher education research (Gonyea, 2005).

Broken down by gender, the sample of this study included $39.5 \%$ males and $60.5 \%$ females. For marital status, $50.8 \%$ of respondents were single, and $49.2 \%$ were married. Faculty belongs to different age groups, respondent age distribution was $44.4 \%$ below 30 years old, $22.6 \%$ from 31 to 35 years old and $16.1 \%$ from 36 to 40 years old. For length of employment in faculties' current position, $41.9 \%$ had from 1 to 5 years and $25.8 \%$ had from 5 to 10 years. For respondent educational attainment, 16.9\% held bachelor's degrees, 72.6\% had master's degrees, and $10.5 \%$ held doctoral degrees. Overall, $75.8 \%$ of respondents were lecturers and $17.7 \%$ of teaching assistant.

\subsection{Variables}

Faculty teaching efficacy identified as the dependent variable in this study. As showed in Table 1, faculty teaching efficacy was composed of six factors such as course design, technology usage, instructional strategy, classroom management, interpersonal relation, and learning assessment. The respondents were asked to rate faculty members' level of teaching efficacy on a 5-point Likert's scale ranging from $1=$ "strongly disagree" to 5 = "strongly agree".

Factor analysis and internal consistency analysis (Cronbach's $\alpha$ ) were conducted to assess the validity and reliability of this constructed measurement for faculty teaching efficacy in USSH-VNUHCM. Table 1 presents that factor loading values of the six factors $(0.64-0.82)$ were higher than the threshold value of 0.5 (Hair, Anderson, Tatham, \& Black, 2009), showing that the six factors were all suitable for constructing teaching efficacy. Internal consistency analysis revealed a Cronbach's coefficient (0.92) higher than the threshold value of 0.7 (Nunnally \& Bernstein, 1994) and 0.6 (Hair et al., 2009) indicating satisfactory reliability. Total variance explained was $72.01 \%$, meeting the requirement of a constructed variable for social science research (Hair et al., 2009). Based on the validation of construct reliability which is concluded that research construct of teaching efficacy is reliable. 
Table 1 . The construct validities and reliabilities of the faculty teaching efficacy

\begin{tabular}{llll}
\hline Factors & Factor loadings & $\begin{array}{l}\text { Variance } \\
\text { explained (\%) }\end{array}$ & Cronbach's $\alpha$ \\
\hline Course design & 0.64 & & \\
Instructional strategy & 0.79 & 72.01 & 0.92 \\
Technology usage & 0.65 & & \\
Classroom management & 0.72 & & \\
Interpersonal relation & 0.69 & & \\
Learning assessment & 0.82 & & \\
\hline
\end{tabular}

The independent variables of this study encompassed two categories such and individual (including gender, age, marital status, length of employment, academic rank, and educational attainment) and organizational environment (see Table 2). The organizational environment factors were four blocks. The first block was teaching resources including teaching support equipment, internet and computer, technology and software, teaching materials, and classroom space. The second block was organizational culture including colleague support, relationship with colleagues, feedback from peers, job autonomy, and efficacy of department meetings. The third block was remuneration policy including faculty promotion, equality in school, salaries, bonus and welfare, and in-service teaching training. The final block was administrative support including care about teaching effectiveness, require high teaching quality, rewards quality teaching, involve teachers' idea, and concerned whether teaching load.

Table 2. Coding schemes and proportions of the independent variables in this study

Factors

\section{A. Individual factors:}

Gender: $1=$ male $; 0=$ female

Marital status: $1=$ single; 2 = married

Age: $1=$ under 30 years; $2=31$ to 35 years; $3=36$ to 40 years; $4=41$ to 45 years; $5=46$ to 50 years; $6=$ over 50 years

Length of employment: 1 = below one year; $2=1$ to 5 years; $3=6$ to 10 years; $4=11$ to 15 years; $5=15$ to 20 years; $6=$ over 20 years

Academic rank: 1 = main lecturer; 2 = lecturer; 3 = teaching assistant

Educational attainment: 1 = doctoral degree; 2 = masters' degree; 3 = bachelors' degree

\section{B. Organizational environment factors}

\section{1) Teaching resources:}




\section{Macrothink}

Education and Linguistics Research

ISSN 2377-1356 2017, Vol. 3, No. 2

Teaching support equipment: measured on a 5-point scale, where $1=$ very dissatisfied to $5=$ very satisfied

Internet and computer: measured on the same scale as that for teaching support equipment

Technology and software: measured on the same scale as that for teaching support equipment

Teaching materials: measured on the same scale as that for teaching support equipment

Classroom space: measured on the same scale as that for teaching support equipment

\section{2) Organizational culture:}

Colleague support: measured on a 5-point scale, where $1=$ very dissatisfied to $5=$ very satisfied

Relationship with colleagues: measured on the same scale as that for colleague support

Feedback from peers: measured on the same scale as that for colleague support

Job autonomy: measured on the same scale as that for colleague support

Efficacy of department meetings: measured on the same scale as that for colleague support

\section{3) Remuneration policy:}

Faculty promotion: measured on a 5-point scale, where $1=$ very dissatisfied to $5=$ very satisfied

Equality in school: measured on the same scale as that for faculty promotion

Salaries: measured on the same scale as that for faculty promotion

Bonus and welfare: measured on the same scale as that for faculty promotion

In-service teaching training: measured on the same scale as that for faculty promotion

\section{4) Administrative support:}

Care about teaching effectiveness: measured on a 5-point scale, where $1=$ very dissatisfied to $5=$ very satisfied

Require high teaching quality: measured on the same scale as that for care about teaching effectiveness

Rewards quality teaching: measured on the same scale as that for care about teaching effectiveness

Involve teachers' idea: measured on the same scale as that for care about teaching effectiveness

Concerned whether teaching load: measured on the same scale as that for care about teaching effectiveness

\subsection{Data Analyses}

This study employed statistical methods of the correlation, independent $t$-test, two-way ANOVA and multiple regression analyses to analyze the data. The correlation analyses were 
computed to understand the relationship of six factors of faculty teaching efficacy. In this study, an independent $t$-test was performed to test the mean differences in teaching efficacy scores across gender of faculty members. The two-way analysis of variance was performed to test the mean differences in the male and female faculty teaching efficacy across individual factors such as marital status, age, length of employment, academic rank, and educational attainment. A series of separate stepwise multiple regression analyses were conducted to analyze the effects of organizational environment factors on male and female faculty teaching efficacy in USSH-VNUHCM.

\section{Results and Discussion}

\subsection{The Correlation between Six Factors of Faculty Teaching Efficacy}

Table 3 shows the correlation among six dimensions of faculty teaching efficacy including course design, technology usage, instructional strategy, classroom management, interpersonal relation, and learning assessment. The value of correlation coefficient ranges from 0.512 to 0.752 was relatively high positive correlation between factors of teaching efficacy. The relationship between instructional strategy and learning assessment $(r=0.752)$ were highest associated. Other significant associations are lowest found between interpersonal relation and course design $(r=0.512)$.

Table 3. The results of correlation between six factors of faculty teaching efficacy

\begin{tabular}{lllllll}
\hline & $\begin{array}{l}\text { Course } \\
\text { design }\end{array}$ & $\begin{array}{l}\text { Instructional } \\
\text { strategy }\end{array}$ & $\begin{array}{l}\text { Technology } \\
\text { usage }\end{array}$ & $\begin{array}{l}\text { Classroom } \\
\text { management }\end{array}$ & $\begin{array}{l}\text { Interpersonal } \\
\text { relation }\end{array}$ & $\begin{array}{l}\text { Learning } \\
\text { assessment }\end{array}$ \\
\hline $\begin{array}{l}\text { Course } \\
\text { design }\end{array}$ & 1 & & & & \\
$\begin{array}{l}\text { Instructional } \\
\text { strategy }\end{array}$ & $.657^{* *}$ & 1 & & & \\
$\begin{array}{l}\text { Technology } \\
\text { usage }\end{array}$ & $.680^{* *}$ & $.646^{* *}$ & 1 & & \\
$\begin{array}{l}\text { Classroom } \\
\text { management }\end{array}$ & $.532^{* *}$ & $.742^{* *}$ & $.576^{* *}$ & 1 & 1 & \\
$\begin{array}{l}\text { Interpersonal } \\
\text { relation }\end{array}$ & $.512^{* *}$ & $.724^{* *}$ & $.555^{* *}$ & $.723^{* *}$ & 1 & \\
$\begin{array}{l}\text { Learning } \\
\text { assessment }\end{array}$ & $.723^{* *}$ & $.752^{* *}$ & $.670^{* *}$ & $.722^{* *}$ & $.722^{* *}$ & 1 \\
\hline
\end{tabular}

Note: ** Correlation is significant at the 0.01 level (2-tailed).

Unfortunately, there is as yet no empirical research on the correlation between factors of faculty teaching efficacy in Vietnam or even in other parts of the world. The finding of this study, therefore, cannot be compared to the findings of others. 
3.2 Comparison among Male and Female Faculty Teaching Efficacy with Different Individual Factors

Regarding the relationship in teaching efficacy between male and female faculty members in USSH-VNUHCM, Table 4 indicates that there were significant differences between the level of teaching efficacy of male and female faculty members $(t=3.371, p<0.01)$. The ranges of scores showed that female faculty was significantly higher than their male colleagues. The results of this study correspond to the results of Chang et al. (2011) and Norton Richardson, Hartley, Newstead, and Mayes (2005). The research of Chang et al. showed that female faculty had more agreeable than their male counterparts in learning assessment. Similarly, Norton et al. found that female faculty felt more confident than their male colleagues in the area of learning assessment. Furthermore, these researches also indicated that female score significantly higher than male faculty in classroom management which disputed in this study. However, Mehdinezhad (2012) shows that there was no significant differences between faculty teaching efficacy and their gender.

Table 4. The results of two-way ANOVA between individual factors and male and female faculty teaching efficacy in USSH-VNUHCM

\begin{tabular}{|c|c|c|c|c|}
\hline & & Gender & & \\
\hline Individual factor & & Male (M) & Female $(\mathrm{F})$ & ANOVA \\
\hline & & & & \\
\hline Gender & & $3.95(.58)$ & $4.26(.43)$ & $3.371 * *(t$-test $)$ \\
\hline & Single & $3.82(.65)$ & $4.16(.39)$ & \\
\hline & Married & $4.13(.42)$ & $4.34(.45)$ & \\
\hline & Under 30 & $3.73(.69)$ & $4.17(.40)$ & \\
\hline & $31-35$ & $3.90(.51)$ & $4.32(.50)$ & \\
\hline & $36-40$ & $4.48(.27)$ & $4.23(.47)$ & \\
\hline Age & $41-45$ & $4.04(.23)$ & $4.60(.26)$ & אכנים \\
\hline & $46-50$ & $3.73(.00)$ & $4.38(.30)$ & \\
\hline & Over 50 & $4.30(.00)$ & $4.30(.37)$ & \\
\hline & Below 1 year & $4.04(.68)$ & $4.21(.31)$ & \\
\hline & $1-5$ & $3.78(.74)$ & $4.24(.49)$ & \\
\hline Length & $6-10$ & $4.08(.43)$ & $4.35(.40)$ & \\
\hline employment & $11-15$ & $4.13(.38)$ & $4.03(.38)$ & טנים \\
\hline & $16-20$ & $3.92(.16)$ & $4.41(.39)$ & \\
\hline & Over 20 & $4.07(.33)$ & $4.38(.37)$ & \\
\hline Academic rank & Main lecturer & $3.83(.00)$ & $4.48(.36)$ & 1.518 \\
\hline
\end{tabular}




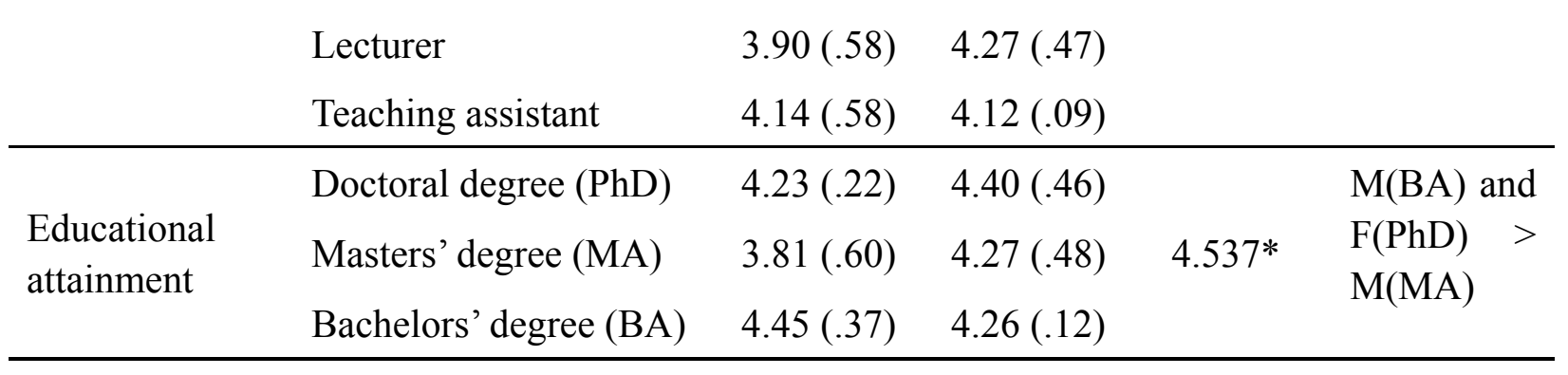

Note. $* p<0.05, * * p<0.01$.

Comparative results of male and female faculty members in various contexts detected using a statistical method and criteria demonstrated that although, there were significant differences between the teaching efficacy of male and female faculty members, but, almost individual factors including marital status, age groups, and academic rank were not significant in the male and female faculty teaching efficacy, except educational attainment factor. Only the educational attainment item of individual factor was significant difference between faculty teaching efficacy across their gender $(F=4.537, p<0.05)$. The findings of Table 4 indicated that male holding bachelors' degree and female holding doctoral degree was significantly higher than their male colleagues who had masters' degree. The studies of the relationship between male and female faculty teaching efficacy and educational attainment item of individual factor are very few in order to discuss with the results of this study. The research of Duong, Nguyen and Nguyen (2017) showed that there were statistical difference between these educational attainment and faculty teaching efficacy in technology usage factor $(F=$ 5.009, $p<0.01)$. The finding post hoc comparison showed that faculty members holding bachelors' degree $(M=4.32, S D=0.37)$ have higher scores in technology usage than those holding masters' degree $(M=3.88, S D=0.61)$. However, the research of Duong et al. investigated that there were significant differences between educational attainment and faculty teaching efficacy, unfortunately, these study were not seen differences between educational attainment and faculty teaching efficacy by their gender.

\subsection{The Effects of Organizational Environment Factors on Male and Female Faculty Teaching Efficacy}

In Table 5, the findings were stepwise regression analyses to clearly present the effects of variable combinations on the teaching efficacy of the Vietnamese faculty members. The results present coefficients of $\beta$ values, with $\beta>0$ indicating a positive effect and $\beta<0$ indicating a negative effect on the teaching efficacy. The different regression models had different explanation for teaching efficacy across different factors of organizational environment. Models 1 through 4 present the separate effects of organizational environment factors on faculty teaching efficacy by gender, and Model 5 involved gender-specific regression analyses to further examine gender differences. Multicollinearity diagnosis yielded no value of variance inflation factor (VIF) in the regression models higher than 10, indicating no risk of serious multicollinearity of the models (Hair et al., 2009). These models explained $83.0 \%$, and $23.0 \%$ of the variance of teaching efficacy of female faculty members and male faculty members, respectively.

Model 1 indicated that the variables of learning resources as a whole did not significantly 
affect the faculty teaching efficacy across their gender. In the Model 2 , colleague support ( $\beta$ $=.67, p<0.01)$ and job autonomy $(\beta=.50, p<0.01)$ items of organizational culture factor had significant positive on the male faculty teaching efficacy and negative effect by efficacy of department meetings item $(\beta=-.30, p<0.05)$, but not that of the female faculty. The results of this study were supported by researches of McKeachie and Svinicki's (2006) and Chang et al. (2010) demonstrated that support from colleagues is one of the best ways to improve teaching quality and promote teaching effectiveness. In addition, Chang et al. also indicated that colleagues whose have the same department or discipline, they can suggest teaching strategies helpful in dealing with areas that needs improvement. Furthermore, colleague support not only broadens and deepens faculty's teaching predilection to promote teaching efficacy but also enhances their socialization within the universities.

For remuneration policy factor in Model 3, male and female faculty teaching efficacy had different impacts by different items of remuneration policy factor. For example, salaries $(\beta=$ $-.65, p<0.05)$ and bonus and welfare $(\beta=.98, p<0.001)$ exerted significant effects on the male faculty teaching efficacy in Vietnamese university. Equality in school item $(\beta=.54, p<$ $0.05)$ showed slight influences on female faculty teaching efficacy. Model 4 demonstrated that care teaching effectiveness $(\beta=.44, p<0.01)$ was also a significant factor benefitting the attainment of female faculty teaching efficacy. Although both male and female teaching efficacy had not effects by items of learning resources factor in the Model 1. Teaching support equipment and internet and computer items significantly benefited the teaching efficacy of the male faculty, but yielded no effect on female faculty teaching efficacy in the Model 5. This finding corresponds to Tschannen-Moran and Woolfolk Hoy (2002) and Chang et al. (2010) indicated that teaching efficacy is weakly related to the teaching support variables (including teaching resources). Teaching support may not be able to enhance teachers' sense of teaching efficacy when they are not clear about their teaching responsibilities or meet the basic needs of instructors. Job autonomy item of organizational culture factor $(\beta=.39, p<0.01$ for male; $\beta=.43, p<0.05$ for female) and care teaching effectiveness item of administrative support factor $(\beta=.73, p<0.01$ for male; $\beta=.54, p<$ 0.05 for female) demonstrated positive impacts on both genders' teaching efficacy. The research of Chang et al. (2010) demonstrated that administrative support makes little contribution to teaching efficacy. When they encounter any difficulty or challenges in teaching, they would rather consult their colleagues than administrators. Thus, there are a distance between the lecturer and administrator. Chang et al. also showed that administrative support is not enough or does not meet what the faculty need.

Note that not all items of organizational environment factors exhibited a significant benefit on faculty teaching efficacy by gender. Faculty promotion item of remuneration policy factor $(\beta=-.36, p<0.05)$ and require high teaching quality item of administrative support factor $(\beta$ $=-.57, p<0.01)$ exhibited a significant hindrance on male faculty teaching efficacy, but not that of the female faculty. There is, however, as yet no empirical research on the regression between organizational environment factors and faculty teaching efficacy by their gender in Vietnam or even in other parts of the world. The finding of this study therefore, cannot be compared to the findings of others. Further research about the relationship between faculty teaching efficacy and university environment factors will contribute to fill in the literature 
gap.

Table 5. Stepwise and gender-specific regression analyses of variable effects on the teaching efficacy of the Vietnamese university faculty members

\begin{tabular}{|c|c|c|c|c|c|c|c|c|c|c|}
\hline \multirow{2}{*}{$\begin{array}{l}\text { Organizational } \\
\text { environment factors }\end{array}$} & \multicolumn{2}{|c|}{ Model 1} & \multicolumn{2}{|c|}{ Model 2} & \multicolumn{2}{|c|}{ Model 3} & \multicolumn{2}{|c|}{ Model 4} & \multicolumn{2}{|c|}{ Model 5} \\
\hline & $\mathrm{M}$ & $\mathrm{F}$ & $\mathrm{M}$ & $\mathrm{F}$ & $\mathrm{M}$ & $\mathrm{F}$ & $\mathrm{M}$ & $\mathrm{F}$ & $\mathrm{M}$ & $\mathrm{F}$ \\
\hline
\end{tabular}

A. Learning resources

Teaching support $\quad .38 \quad .23$

Internet and $\quad-.03 \quad .02$

$.54 * * .14$

computer

Technology

$-.01-.01$

$.17 \quad .01$

Teaching materials $\quad .33 \quad .30$

$-.19 \quad .02$

Classroom space

$\begin{array}{ll}-.09 & -.19\end{array}$

$.26 \quad-.32$

B. Organizational culture

Colleague support

Relationship with

colleagues

Feedback from

peers

Job autonomy

$.50 * * \quad .27$

Efficacy of

$-.30 * .08$

department

C. Remuneration policy

Faculty promotion

Equality in school

Salaries

Bonus and welfare

In-service teaching

D. Administrative support

Care teaching

Require high quality

Rewards quality

teaching

Involve teachers'

idea

$-.36 \quad .12$

$.17 \quad .19$
$.67 * *-.13$

$.89 \quad-.24$

$.20 \quad .08$

$.54 \quad .01$

$.39 * * .43 *$

$-.15 \quad-.12$

$-.10 \quad-.18$

$-.36 * \quad-.24$

$.13 \quad .54 *$

.09

.42

$-.65 * \quad-.14$

$\begin{array}{ll}-.08 & -.33\end{array}$

$.98 * * * \quad .12$

.34

.21

$-.06 \quad .03$

$-.20$

.16

$.82 \quad .44 * * \quad .73 * * \quad .54 *$

$\begin{array}{llll}-.63 & -.12 & -.57 * * & -.17\end{array}$

$\begin{array}{llll}.27 & .17 & .27 & .12\end{array}$

$\begin{array}{llll}-.23 & -.15 & -.25 & -.19\end{array}$ 
Concerned whether

teaching load

\begin{tabular}{lllllllllll}
\hline $\mathrm{R}^{2}$ & .32 & .12 & .54 & .24 & .28 & .16 & .60 & .28 & .90 & .44 \\
Adj. $\mathrm{R}^{2}$ & .24 & .06 & .49 & .18 & .19 & .09 & .56 & .23 & .83 & .23 \\
\hline
\end{tabular}

Note. $* p<.05, * * p<.01, * * * p<.001$.

\section{Conclusion}

Responding to research questions posed in the current study, it examined the correlation between factors of teaching efficacy and their relation to faculty members' backgrounds, and how organizational environment factors affect faculty teaching efficacy in male versus female populations. The findings of this study showed that the correlation between factors of teaching efficacy were relatively high positive. Except educational attainment item, almost other items of individual factor including marital status, age groups, and academic rank were not significant in the male and female faculty teaching efficacy. In addition, organizational environment factors had significant effects on male and female teaching efficacy. The different factors had different effects on male and female faculty teaching efficacy in Vietnam. Hence, when university managers and policy makers want to improve a universal intervention to enhance faculty teaching efficacy, they should be notably concerned about both these factors.

The primary limitation is that only USSH-VNUHCM faculty members were sampled in this study, and thus, the results and implications should be applied with caution to faculty members from different levels of higher education institutes or academic disciplines. Further research should collect faculty member samples from various higher education levels and disciplines. It is hoped that the barrier to the male and female faculty teaching efficacy are found in this study may be useful for university management to develop work environment and culture that would allow higher levels of faculty teaching efficacy and can contribute to a great extent to improve the level of faculty members in Vietnamese higher education.

\section{Acknowledgment}

I would like to acknowledge my sincere gratitude to anonymous, kindest support and help, valuable advice, synthesized comments on revision, and detailed editing throughout.

\section{References}

Allinder, R. M. (1994). The relationship between efficacy and the instructional practices of special education teachers and consultants. Teacher Education and Special Education, 17(2), 86-95. https://doi.org/10.1177/088840649401700203

Ashton, P. T., \& Webb, R. B. (1986). Making a difference: Teachers'sense of efficacy and student achievement. White Plains, NY: Longman.

Bandura, A. (1986). Social foundations of thought and action: A social cognitive theory. Englewood Cliffs, NJ: Prentice-Hall.

Bandura, A. (1997). Self-efficacy: The exercise of control. New York: Freeman.

Brouwers, A., \& Tomic, W. (2003). A test of the factorial validity of the Teacher Efficacy 
Scale. Research in Education, 69, 67-79. https://doi.org/10.7227/RIE.69.6

Brown, G. (1993). Effective teaching. In R. Ellis (Ed.) Quality assurance for university teaching (pp. 211-232). Bristol, PA: Open University Press.

Carara, G., Barbaranelli, C., Steca, P., \& Malone, P. (2006). Teachers' self-efficacy beliefs as determinants of job satisfaction and students' academic achievement: a study at the school level. Journal of School Psychology, 44(1), 473-90. https://doi.org/10.1016/j.jsp.2006.09.001

Chang, T. S., McKeachie, W., \& Lin, Y. G. (2010). Faculty perceptions of teaching support and teaching efficacy in Taiwan. Higher Education, 59, 207-220. https://doi.org/10.1007/s10734-009-9243-8

Chang, T. S; Lin, H. H; \& Song, M. M. (2011). University faculty members' perceptions of their teaching efficacy. Innovations in Education and Teaching International, 48(1), 49-60. https://doi.org/10.1080/14703297.2010.543770

Cook, P. (1998). The influence of organizational characteristics of faculty teaching self-efficacy. Unpublished doctoral dissertation. Vanderbilt University, Nashville, Tennessee.

Darling-Hammond, L., Chung, R., \& Frelow, F. (2002). Variation in teacher preparation: How well do different pathways prepare teachers to teach? Journal of Teacher Education, 53(4), 286-302. https://doi.org/10.1177/0022487102053004002

Duong, M. Q., Nguyen, T. A., \& Nguyen, H. P. (2017). Demography factors and faculty members' teaching efficacy in Vietnamese higher education. Journal of Studies in Education, 7(1), 17-31. https://doi.org/10.5296/jse.v7i1.10397

Esterly, E. J. (2003). A multi-method exploration of the mathematics teaching efficacy and epistemological beliefs of elementary preservice and novice teachers. Unpublished Ph.D Dissertation, Ohio State University, Ohio.

Giallo, R., \& Little, E. (2003). Classroom behavior problems: the relationship between preparedness, classroom experiences, and self-efficacy in graduate and student teachers. Australian Journal of Educational \& Developmental Psychology, 3(1), 21-34.

Gibson, S. \& Dembo, M., (1984). Teacher efficacy: A construct validation. Journal of Educational Psychology, 76(4), 569-582. https://doi.org/10.1037/0022-0663.76.4.569

Gkolia, A., Belias, D., \& Koustelios, A. (2014). Teacher's job satisfaction and self-efficacy: A review. European Scientific Journal, 10(22), 321-342.

Goddard, R. D., Hoy, W. K., \& Woolfolk Hoy, W. (2000). Collective teacher efficacy: Its meaning measure, and impact on student achievement. American Educational Research Journal, 37(2), 479-507. https://doi.org/10.3102/00028312037002479

Gonyea, R. M. (2005). Self-reported data in institutional research: Review and recommendations. In P. D. Umbach (Ed.), Servey research: Emerging issues (pp. 73-89). San Francisco, CA: Jossey-Bass. https://doi.org/10.1002/ir.156

Gow, L., \& Kember, D. (1993). Conceptions of teaching and their relationship to student learning. The British Journal of Educational Psychology, 63, 20-33. https://doi.org/10.1111/j.2044-8279.1993.tb01039.x

Hair, J. F., Anderson, R. E., Tatham, R. L., \& Black, W. C. (2009). Multivariate data analysis (6th ed.). New Jersey: Prentice Hall. 
Hayden. M \& Lam. T. (2007). Institutional autonomy for higher education in Vietnam.

Higher Education Research \& Development, 26(1), 73-85. https://doi.org/10.1080/07294360601166828

Henson, K. (2001). Relationships between pre-service teachers' self-efficacy, task analysis, and classroom management beliefs. Paper presented at the Annual Meeting of the Southwest Educational Research Association, New Orleans

Kim, E. (2009). Beyond language barriers: Teaching self-efficacy among East Asian international teaching assistants. International Journal of Teaching and Learning in Higher Education, 21(2), 171-180.

Lin, H. L., \& Gorrell, J. (2001). Exploratory analysis of pre-service teacher efficacy in Taiwan. Teaching and Teacher Education, 17(5), 623-635. https://doi.org/10.1016/S0742-051X(01)00018-X

Marsh, H. W., \& Hattie, J. (2003). The relation between research productivity and teaching effectiveness: Complementary, Antagonistic, or independent constructs? The Journal of Higher Education, 73(5), 603-641. https://doi.org/10.1080/00221546.2002.11777170

McKeachie, W. J., \& Svinicki, M. (2006). McKeachie's teaching tips: Strategies, research, and theory for college and university teachers (12th ed.). Boston: Houghton Mifflin.

Mehdinezhad, V. (2012). Faculty members' understanding of teaching efficacy criteria. Education Inquiry, 3(1), 49-69. https://doi.org/10.3402/edui.v3i1.22013

Ngo, T. M., Lingard, B., \& Mitchell, J. (2006). The policy cycle and vernacular globalization: a case study of the creation of Vietnam National University-Hochiminh City. Comparative Education, 42(02), 225-242. https://doi.org/10.1080/03050060600628082

Nolen, S., Ward, C., Horn, I., Campbel, S., Mahna, K., \& Childers, S. (2007). Motivation to learn during student teaching. Paper presented at the annual meeting of the American Educational Research Association, Chicago.

Norton, L., Richardson, J., Hartley, J., Newstead, S., \& Mayes, J. (2005). Teachers' beliefs and intentions concerning teaching in higher education. Higher Education, 50(4), 537-571. https://doi.org/10.1007/s10734-004-6363-z

Nunnally, J. C., \& Bernstein, I. H. (1994). Psychometric theory (2nd ed.). New York, NY: McGraw-Hill.

Shen, J. (1997). Mission involvement and promotion criteria in schools, colleges, and departments of education. American Journal of Education, 104, 186-211. https://doi.org/10.1086/444152

Ross, J. A. (1994). Beliefs that make a difference: The origins and impacts of teacher efficacy. Paper presented at the annual meeting of the Canadian Association for Curriculum Studies.

Ross, J., \& Bruce, C. (2007). Professional development effects on teacher efficacy: Results of randomized field trial. The Journal of Educational Research, 101(1), 50-60. https://doi.org/10.3200/JOER.101.1.50-60

The National Assembly. (2012). The Law on Higher Education in Vietnam (Law No. 08/2012/QH13). Retrieved from http://www.hcmiu.edu.vn/Portals/1/Docs/vanbanphapluat/english/08-2012-QH13-Luat\%20G 


\section{Macrothink}

DDH.pdf

Tschannen-Moran, M., \& Woolfolk Hoy, A. (2001). Teacher efficacy: Capturing an elusive construct. Teaching and Teacher Education, 17, 783-805. https://doi.org/10.1016/S0742-051X(01)00036-1

Tschannen-Moran, M., \& Woolfolk Hoy, A. (2002). The influence of resources and support on teachers' efficacy beliefs. Paper presented at the annual meeting of the American Educational Research Association, New Orleans, LA.

Tschannen-Moran, M., Woolfolk Hoy, A., \& Hoy, W. K. (1998). Teacher efficacy: Its meaning and measure. Review of Education Research, 68(2), 202-248. https://doi.org/10.3102/00346543068002202

Tournaki, N., \& Podell, D. M. (2005). The impact of student characteristics and teacher efficacy on teachers' predictions of student success. Teaching and Teacher Education, 21, 299-314. https://doi.org/10.1016/j.tate.2005.01.003

Usher, E. \& Pajares, F. (2006). Inviting confidence in school: invitations as a critical source of the academic self-efficacy beliefs of entering middle school students. Emory University Journal of Invitational Theory and Practice, 12, 7-16.

Woolfolk, H. A. (2004). Self-efficacy in college teaching. Essays on Teaching Excellence: Toward the Best in the Academy, 15(7), 8-11. Fort Collins, CO: The POD Network.

Woolfolk-Hoy, A., \& Davis, H. (2006). Teacher self-efficacy and its influence on the achievement of adolescents. In F. Pajares, \& T. Urdan (Ed.), Self-efficacy beliefs of adolescents, (pp. 117-138). Charlotte, NC: Information Age.

\section{Copyright Disclaimer}

Copyright reserved by the author(s).

This article is an open-access article distributed under the terms and conditions of the Creative Commons Attribution license (http://creativecommons.org/licenses/by/3.0/). 